\title{
Study on Spatial Distribution Characteristics and Influencing Factors of Cultural and Creative Industries in Zhejiang Province
}

\author{
Di Lv", Yue Qin \\ Ningbo University of Finance \& Economics, China \\ ${ }^{*}$ Corresponding author
}

\begin{abstract}
The agglomeration of cultural and creative industries has developed into a remarkable trend under economic internationalization. In this paper, literature review and research status of cultural and creative industries are firstly conducted. The spatial distribution characteristics of cultural and creative industries in Zhejiang province are analyzed by using location entropy and data from 2012 to 2017. The conclusion shows that the cultural and creative industries in Zhejiang province present a spatial clustering trend, but different cities have different development levels. This paper constructs the indicator system of influencing factors and analyzes its influencing factors by means of grey correlation. It shows that economic factors have the greatest influence on the agglomeration of cultural and creative industries, followed by technological, resource and market factors. The development and agglomeration of the cultural and creative industry in Zhejiang province depends on the development of industry, the application and management of information technology and the lack of creative talents is the obstacle to its development. Therefore, education should be developed, mass innovation should be encouraged, and a good market environment should be created for the cultural and creative industry.
\end{abstract}

Key words: Cultural and creative industry agglomeration, spatial distribution, influencing factors, grey correlation, industry

\section{Introduction}

In response to the proposal of "building a socialist powerful cultural country" at the 19th National Congress, Opinions on Accelerating the Development of Cultural Industry into a Trillion-level Industry was issued by Zhejiang Provincial Party Committee and the provincial government, which expressed the firm determination to build a cultural Zhejiang and vigorously cultivate a trillion-level cultural industry. Cultural and creative industries in Zhejiang Province are a significant component of cultural industries, which have made great achievements under the favorable policy circumstance. In 2017, the province's cultural and creative industries have an added value of 323.3 billion yuan, an increase of $13.1 \%$, accounting for $6.8 \%$ of GDP, becoming the new engine of national economic growth in Zhejiang Province. So, are the cultural and creative industries in Zhejiang Province clustered? Is the degree of agglomeration of each prefecture-level city the same? What are the factors affecting its industrial agglomeration? These problems have become the focus worth exploring.

In this paper, the above problems are summarized as: (1) the distribution and characteristic of cultural and creative industries in various prefecture-level cities in Zhejiang Province; (2) Influencing factors of agglomeration and development of cultural and creative industry. The data in this paper are derived from Zhejiang Statistical Yearbook, China Statistical Yearbook, and the regional statistical yearbooks of 11 prefecture-level cities in Zhejiang from 2013 to 2018. The data related to cultural and creative industries are replaced by the data related to software industry, computer services, information transmission, culture, sports and entertainment industry with reference to Chi Jianyu (2013) as the data types used in the statistics of 11 cities in Zhejiang Province are different.

\section{Literature Review}

Shahid Yusuf and Kaoru (2005) analyzed the development trend of cultural industry in various countries from the

ISSN: 0010-8189 
aspects of human resources, market differences, openness and industrial structure differences. Molina et al. (2012) estimated that there is a high concentration of cultural and creative industries in some regions. Feng Zhen (2016) provided the suggestions for the development and innovation of cultural and creative industries in Wuxi after analyzing the current situation of Wuxi's cultural and creative industry agglomeration and the macro, industrial and market factors of industrial agglomeration development [1]. Zhang Zhenjie (2017) believed that the cultural and creative industries in Zhejiang, Jiangsu, Shanghai are mainly concentrated in northern Zhejiang, southern Jiangsu and are influenced by factors such as talents, science and technology, environment, tolerance, policies, infrastructure and market [2]. Zhou Jin and Wen Wen (2012) used factor analysis to study the development and innovation of Chinese culture industry, and concluded that the development and innovation of Chinese culture industry depend on infrastructure, cultural talents, cultural resources, related industries and economy.

Although researchers at home and abroad have discussed the development, innovation and influencing factors of culture and creativity industries agglomeration from various angles, different countries have different standards for defining cultural and creative industries, and there are few empirical studies of influencing factors of cultural and creative industries agglomeration due to the late start of Chinese culture and creativity industries, and even fewer special studies on Zhejiang region. In this paper, based on previous studies, the location entropy is used to measure the distribution and the grey correlation is used to analyze the influence of economic, resources, technology, market and other factors, which is of great significance for the sustainable development and innovation of culture and creativity industries in Zhejiang Province.

\section{Analysis on Spatial Distribution and Characteristics of Culture and Creativity Industry Agglomeration in Zhejiang Province}

\subsection{Methodology}

There are many methods to measure the level of industrial agglomeration. In this paper, location entropy, as specialization rate which was provided by Haggett for location analysis, is often used in regional economics to judge whether an industry constitutes regional specialization and measure the specialized division of labor in a certain region to determine advantageous industries [3]. In order to intuitively reflect the output value proportion of an industry in a certain region to that of the entire province or the whole country, the calculation formula is as follows:

$$
U_{i j}=\frac{x_{i j} / x_{i}}{X_{i j} / X_{i}}
$$

Where,

$U_{i j}=$ the location entropy of industry $\mathrm{j}$ in region $\mathrm{i}$;

$x_{i j}=$ the indicator of industry $\mathrm{j}$ in region $\mathrm{i}$;

$x_{i}=$ the indicators of all the industries in region $\mathrm{i}$;

$X_{i j}=$ the indicator of industry $\mathrm{j}$ in the province or country where region $\mathrm{i}$ is located;

$X_{i}=$ the indicators of all the industries in the province or country where region $\mathrm{i}$ is located.

$U_{i j}>1$ indicates that there is industrial agglomeration in this industry in region $\mathrm{i}$.

In this paper, industry $\mathrm{j}$ is a culture and creativity industry, the numerator is the relevant indicators of culture and creativity industries in Zhejiang, and the denominator is the ratio of the indicators of culture and creativity industries in Zhejiang Province to all their output values. As it is difficult to collect the income data of cultural and creative industries in Zhejiang Province, only the number of employed people in culture and creativity industries is selected to calculate the location entropy, referred to as CIA(EMP), and the agglomeration level of culture and creativity industries in Zhejiang Province is normalized for ease of comparison.

ISSN: 0010-8189 


\subsection{Characteristics analysis}

On the whole, from the agglomeration level of culture and creativity industries in Zhejiang Province listed in Table 1, Hangzhou, Zhoushan and Wenzhou have high agglomeration degree and obvious industrial advantages, but the industrial advantages of each city are significantly different due to the unbalanced development of the region.

First, on average, the location entropy index of Hangzhou (2.19), Zhoushan (1.34) and Wenzhou (1.30) is greater than 1 , indicating a higher level than the average agglomeration level of the province, indicating that the culture and creativity industries in the three cities can not only meet their own regional needs, but also be exported externally. Besides, the regional culture and creativity industries have a high degree of specialization and are in a dominant position in the same industry in Zhejiang Province. Moreover, the spatial distribution of the industries in the three cities shows a trend of agglomeration. Especially in Hangzhou, the location entropy is even higher than 2 , which is far ahead of other cities.

Secondly, the average location entropy index of most cities is greater than 0.5 and close to 1 , which shows that the agglomeration level of culture and creativity industries is high, and the industrial spatial distribution tends to be concentrated. Furthermore, it is obvious that the advantages of culture and creativity industries in Hangzhou have been maintained from 2012 to 2017, with unlimited potential. Looking at the whole table, the highest location entropy index is 2.13 in Hangzhou in 2017, and the lowest is only 0.2 in Taizhou in 2012, with a difference of more than 10 times, indicating the unbalance and serious polarization of the distribution of culture and creativity industries in Zhejiang Province.

Table 1 Location entropy CIA (EMP)

\begin{tabular}{cccccccc}
\hline CIA(EMP) & In 2012 & In 2013 & In 2014 & In 2015 & In 2016 & In 2017 & Mean \\
\hline Zhejiang Province & 1.00 & 1.00 & 1.00 & 1.00 & 1.00 & 1.00 & 1.00 \\
Hangzhou & 2.12 & 2.16 & 2.18 & 2.20 & 2.22 & 2.23 & 2.19 \\
Ningbo & 0.95 & 0.95 & 0.95 & 1.02 & 1.02 & 1.02 & 0.99 \\
Wenzhou & 1.20 & 1.22 & 1.22 & 1.32 & 1.40 & 1.42 & 1.30 \\
Jiaxing & 0.63 & 0.61 & 0.70 & 0.72 & 0.72 & 0.72 & 0.68 \\
Huzhou & 0.77 & 0.78 & 0.78 & 0.76 & 0.75 & 0.75 & 0.77 \\
Shaoxing & 0.56 & 0.62 & 0.68 & 0.75 & 0.73 & 0.78 & 0.69 \\
Jinhua & 0.58 & 0.60 & 0.62 & 0.65 & 0.66 & 0.68 & 0.63 \\
Quzhou & 0.31 & 0.33 & 0.35 & 0.40 & 0.45 & 0.49 & 0.39 \\
Zhoushan & 1.23 & 1.32 & 1.32 & 1.35 & 1.40 & 1.42 & 1.34 \\
Taizhou & 0.20 & 0.23 & 0.25 & 0.28 & 0.29 & 0.29 & 0.26 \\
Lishui & 0.54 & 0.56 & 0.58 & 0.59 & 0.60 & 0.62 & 0.58 \\
\hline
\end{tabular}

From Fig. 1 below, the evolution trend shows that, in general, the level of culture and creativity industries agglomeration in Zhejiang cities is increasing with the increase of time, showing a strong trend of agglomeration, and the level in each city changes smoothly. Among them, Wenzhou, Shaoxing and Zhoushan grow faster and maintain a high-speed gathering situation. Taizhou has a worrying location entropy index and keeps low-speed agglomeration. Compared with the same industries in the whole province, its cultural and creative industries have weak industrial advantages, low specialization and scattered industrial spatial distribution. Therefore, attention should be paid to it and more investment should be found. The culture and creativity industries in other cities have developed well with steady growth.

\section{Analysis on Influencing Factors of Culture and Creativity Industry Agglomeration in Zhejiang Province}

\subsection{Indicators}

Culture and creativity industry is a new industry which is influenced by many factors and involves a collection of various characteristic elements ${ }^{[4]}$, in which economic and resource factors play a fundamental role, technology is 
the key and market environment is the support ${ }^{[5]}$. According to the actual situation of agglomeration level in Zhejiang Province and the relevant findings of domestic and foreign researchers, the influencing factors are divided into four categories, namely, economic factors, resource factors, technical factors and market factors, which are further subdivided into two-level indicators for constructing an indicator system of influencing factors of cultural and creative industry agglomeration (see Table 2).

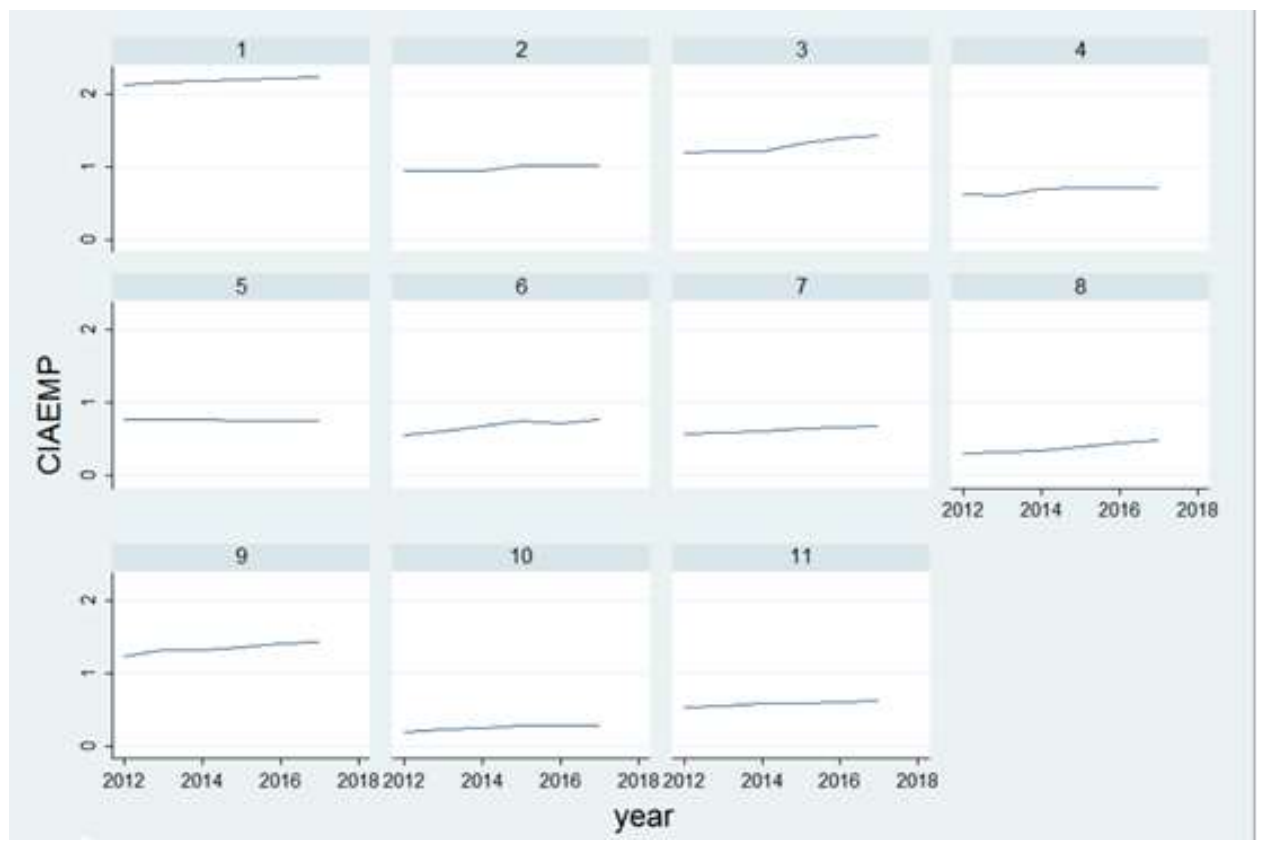

Fig. 1 Evolution trend of industrial agglomeration

(Note: 1. Hangzhou, 2. Ningbo, 3. Wenzhou, 4. Jiaxing, 5. Huzhou, 6. Shaoxing, 7. Jinhua, 8. Quzhou, 9. Zhoushan, 10. Taizhou, 11. Lishui)

Table 2 Factors affecting the agglomeration of cultural and creative industries

\begin{tabular}{|c|c|c|}
\hline \multirow{5}{*}{$\begin{array}{l}\text { Indicator system of } \\
\text { influencing factors } \\
\text { of cultural and } \\
\text { creative industry } \\
\text { agglomeration }\end{array}$} & Main factors & Specific variables and symbols \\
\hline & $\begin{array}{l}\text { Economic } \\
\text { factors }\end{array}$ & $\begin{array}{l}\text { GDP per capita (yuan) } \mathrm{X}_{1} \\
\text { Per capita disposable income of urban residents (yuan) } \mathrm{X}_{2} \\
\text { Social labor productivity }\left(10,000 \text { yuan/person) } \mathrm{X}_{3}\right.\end{array}$ \\
\hline & $\begin{array}{l}\text { Resource } \\
\text { factors }\end{array}$ & $\begin{array}{l}\text { Investment in fixed assets of culture and creativity industries (100 million } \\
\text { yuan) } \mathrm{X}_{4} \\
\text { Number of college students per thousand people (person) } \mathrm{X}_{5} \\
\text { Professional and technical personnel in cultural and creative industries } \\
\left(10,000 \text { people) } \mathrm{X}_{6}\right.\end{array}$ \\
\hline & $\begin{array}{l}\text { Technical } \\
\text { factors }\end{array}$ & $\begin{array}{l}\text { Per capita postal and telecommunication expenses (yuan/person) } \mathrm{X}_{7} \\
\text { Proportion of R\&D expenditure to GDP of the whole province }(\%) \mathrm{X}_{8}\end{array}$ \\
\hline & Market factors & $\begin{array}{l}\text { The proportion of non-state-owned employees in culture and creativity } \\
\text { industries to the employed population in culture and creativity industries } \\
\qquad(\%) \mathrm{X}_{9} \\
\text { Per capita ratio of education, culture and entertainment of urban residents } \\
\text { to consumption expenditure }(\%) \mathrm{X}_{10}\end{array}$ \\
\hline
\end{tabular}

\subsection{Data and processing}

The factors that affect the agglomeration level of culture and creativity industries in our province are analyzed using grey correlation analysis. According to the principles, the first step is to determine the reference sequence reflecting the characteristics of systematic behavior and comparative sequence that consists of the factors that affect systematic behavior. In this paper, the relevant data of Zhejiang province from 2012 to 2017 are taken as samples, and the agglomeration level of culture and creativity industries in Zhejiang province regards as a 
reference sequence, which is denoted as $X_{0}$, and 10 variables $X_{i}(i=1,2,3, \ldots, 10)$ which affect the agglomeration level of culture and creativity industries are deemed as comparative sequences. The time series after sorting is shown in Table 3.

Due to the different physical meanings of the above variables, the dimensions of data also differ, which is not conducive to the analysis table or it is difficult to get the correct conclusion during the comparison. Therefore, the original data should be dimensionless when carrying out grey relational analysis. In this paper, the data are processed by averaging (as shown in Table 4), so that the 10 indicators are in the same order of magnitude, which increases the comparability and reliability of analysis.

Table 3 Time series of each variable

\begin{tabular}{ccccccc}
\hline Years & 2012 & 2013 & 2014 & 2015 & 2016 & 2017 \\
\hline $\mathrm{X}_{0}$ & 3.20 & 2.59 & 2.74 & 3.24 & 3.80 & 4.20 \\
$\mathrm{X}_{1}$ & 63508 & 68805 & 73002 & 77644 & 84916 & 92507 \\
$\mathrm{X}_{2}$ & 34550 & 37080 & 40393 & 43714 & 47237 & 51261 \\
$\mathrm{X}_{3}$ & 9.31 & 10.18 & 10.82 & 11.49 & 12.57 & 13.64 \\
$\mathrm{X}_{4}$ & 318.76 & 404.96 & 494.97 & 586.63 & 708.81 & 821.50 \\
$\mathrm{X}_{5}$ & 18.02 & 18.51 & 18.86 & 19.04 & 19.11 & 19.15 \\
$\mathrm{X}_{6}$ & 3.37 & 3.18 & 3.45 & 3.60 & 3.67 & 3.67 \\
$\mathrm{X}_{7}$ & 1637 & 1836 & 1987 & 2168 & 2519 & 2745 \\
$\mathrm{X}_{8}$ & 2.08 & 2.16 & 2.26 & 2.36 & 2.39 & 2.45 \\
$\mathrm{X}_{9}$ & 23.82 & 26.54 & 26.73 & 23.74 & 20.78 & 21.66 \\
$\mathrm{X}_{10}$ & 13.91 & 11.28 & 9.70 & 10.34 & 11.48 & 11.03 \\
\hline
\end{tabular}

Table 4 Dimensionless treatment

\begin{tabular}{ccccccc}
\hline Years & 2012 & 2013 & 2014 & 2015 & 2016 & 2017 \\
\hline $\mathrm{X}_{0}$ & 0.97 & 0.79 & 0.83 & 0.98 & 1.15 & 1.27 \\
$\mathrm{X}_{1}$ & 0.83 & 0.90 & 0.95 & 1.01 & 1.11 & 1.21 \\
$\mathrm{X}_{2}$ & 0.82 & 0.88 & 0.95 & 1.03 & 1.11 & 1.21 \\
$\mathrm{X}_{3}$ & 0.82 & 0.90 & 0.95 & 1.01 & 1.11 & 1.20 \\
$\mathrm{X}_{4}$ & 0.57 & 0.73 & 0.89 & 1.06 & 1.27 & 1.48 \\
$\mathrm{X}_{5}$ & 0.96 & 0.99 & 1.00 & 1.01 & 1.02 & 1.02 \\
$\mathrm{X}_{6}$ & 0.97 & 0.91 & 0.99 & 1.03 & 1.05 & 1.05 \\
$\mathrm{X}_{7}$ & 0.76 & 0.85 & 0.92 & 1.01 & 1.17 & 1.28 \\
$\mathrm{X}_{8}$ & 0.91 & 0.95 & 0.99 & 1.03 & 1.05 & 1.07 \\
$\mathrm{X}_{9}$ & 1.00 & 1.11 & 1.12 & 0.99 & 0.87 & 0.91 \\
$\mathrm{X}_{10}$ & 1.23 & 1.00 & 0.86 & 0.92 & 1.02 & 0.98 \\
\hline
\end{tabular}

4.3 Grey correlation analysis

After dimensionless processing of the data, according to the grey correlation coefficient formula:

$$
\varepsilon_{0 i}(t)=\frac{\min _{i} \min \left|x_{0}(t)-x_{i}(t)\right|+\xi_{i} \max _{i} \max \left|x_{0}(t)-x_{i}(t)\right|}{\left|x_{0}(t)-x_{i}(t)\right|+\xi_{i}^{\max \max \left|x_{0}(t)-x_{i}(t)\right|}}
$$

and the correlation formula

The correlation is calculated.

$$
\gamma_{0 i}=\frac{1}{6} \sum_{t=2012}^{2017} \varepsilon_{0 i}(t)
$$

\section{Where}

ISSN: 0010-8189 
$\mathrm{i}=1,2, \ldots, 10 ; \mathrm{t}=2012,2013, \ldots, 2017$;

$\xi=$ the identification coefficient, $\xi \in(0,1), \xi=0.5$ here.

The correlation coefficient and degree between culture and creativity industry agglomeration, as well as various influencing factors in Zhejiang Province are shown in Table 5.

Table 5 shows that the grey correlation degree between the agglomeration of culture and creativity industries in Zhejiang Province and its influencing factors is ranked as: per capita postal and telecommunication expenses > per capita GDP > per capita disposable income of urban residents > social labor productivity > professional and technical personnel of cultural and creative industries $>$ number of college students per thousand population > proportion of R\&D expenditure to GDP of the whole province > investment in fixed assets of culture and creativity industries > proportion of per capita education, culture and entertainment of urban residents > proportion of non-state-owned employees in culture and creativity industries to employed population in culture and creativity industries.

An overview of whole table reveals that the gray correlation degree of all indicators is higher than 0.5 , indicating that the selected indicators have a high correlation degree with the agglomeration level of culture and creativity industries and impact them significantly, and that the selected indicators are scientific and reasonable.

Table 5 Grey correlation coefficient and correlation degree between culture and creativity industry agglomeration and various influencing factors in Zhejiang Province

\begin{tabular}{c|ccccccccc}
\hline Indicators & \multicolumn{2}{c}{2012} & 2013 & 2014 & 2015 & 2016 & 2017 & $\begin{array}{c}\text { Grey correlation } \\
\text { coefficient }\end{array}$ & Ranking \\
\hline \multirow{2}{*}{$\begin{array}{c}\text { Economic } \\
\text { factors }\end{array}$} & $\mathrm{X}_{1}$ & 0.582 & 0.644 & 0.625 & 0.875 & 0.811 & 0.743 & 0.713 & 2 \\
& $\mathrm{X}_{2}$ & 0.562 & 0.692 & 0.622 & 0.805 & 0.839 & 0.755 & 0.712 & 3 \\
& $\mathrm{X}_{3}$ & 0.572 & 0.641 & 0.619 & 0.868 & 0.819 & 0.737 & 0.709 & 4 \\
\hline \multirow{2}{*}{ Resource } & $\mathrm{X}_{4}$ & 0.335 & 0.776 & 0.773 & 0.736 & 0.622 & 0.496 & 0.623 & 8 \\
factors & $\mathrm{X}_{5}$ & 0.945 & 0.501 & 0.537 & 0.868 & 0.596 & 0.440 & 0.648 & 6 \\
\hline Technical & $\mathrm{X}_{6}$ & 0.973 & 0.615 & 0.560 & 0.806 & 0.663 & 0.473 & 0.682 & 5 \\
factors & $\mathrm{X}_{7}$ & 0.489 & 0.745 & 0.682 & 0.886 & 0.913 & 0.986 & 0.783 & 1 \\
\hline Market & $\mathrm{X}_{8}$ & 0.769 & 0.556 & 0.558 & 0.799 & 0.652 & 0.498 & 0.639 & 7 \\
factors & $\mathrm{X}_{9}$ & 0.883 & 0.381 & 0.410 & 0.948 & 0.414 & 0.352 & 0.565 & 10 \\
\hline
\end{tabular}

Among the many indicators, the three indicators of economic factors rank high. Obviously, economic aspects show the greatest influences on the agglomeration level of culture and creativity industries, indicating that the level of urban economic development and the agglomeration level of culture and creativity industries show a strong positive relationship, playing a determining factor in the industrial development and innovation. Zhejiang's economic level is among the highest in the country. In 2017, the per capita GDP reached 92,507 yuan, while the per capita disposable income of urban residents grew by 8.5\%, and exceeded 50,000 yuan for the first time. The steady development of economy has enriched people's material life, stimulated people's cultural needs and promoted the development of culture and creativity industries. Culture and creativity industry is an industry that requires a large amount of capital and cost, in which basic activities such as personnel training, department construction, market development and purchase of facilities and equipment all need a lot of capital. In a manner of speaking, fund pool is the lifeblood of cultural industry, so it is necessary to increase economic support for cultural and creative industry to provide guarantee for its sustainable development.

The influence of technical factors of agglomeration development and innovation of culture and creativity industries ranks second, indicating that technical factors are also affecting the industrial layout. From 2012 to 2017 , the proportion of per capita postal and telecommunication expenditure and R\&D expenditure in the province's GDP increased year by year, indicating that the informationization level and R\&D level of Zhejiang Province have been improved significantly, and the radio, television, film and animation industries in Zhejiang Province have been

ISSN: 0010-8189 
continuously improved with the support of technology. In 2018, a total of 52 TV dramas with 2,358 episodes were produced in the province, ranking first in the country for the first time in terms of output, and 54 cartoons with 1,799 episodes were produced, among which 15 cartoons were promoted by the State Administration of Radio, Film and Television, ranking first in the country. The development of culture and creativity industries follows closely the trend of the Internet era. As far as culture and creativity industries are concerned, it is impossible to exchange information and creativity with the outside world without information technology, which is tantamount to cutting off the source of creativity. Therefore, it is necessary to accelerate the alliance of technology and culture and creativity industries, broaden the development space of culture and creativity industries, making mutual exchanges and products created by culture and creativity industries more convenient.

The grey correlation degree of each indicator of resource factors ranks in the middle and lower, and its influence on the development and innovation of culture and creativity industries ranks third. Among all the resource factors, human resources have the greatest impact on culture and creativity industries and are the core resources. Human resources can be specifically divided into ordinary college students and employees in cultural and creative industries. Those who engage in the industries of culture and creativity should have corresponding knowledge, which is a basic requirement for knowledge-intensive industries. In 2017, there were 1,047,000 professional and technical personnel in enterprises and institutions in the province, but only 36,700 in culture and creativity industries, accounting for only 3.5\%. Per 1,000 people involve less than 20 college majors, indicating that the culture and creativity industries of former province lacked high-quality creative talents, which limited the innovation of culture and creativity industries and made unhealthy effect on long-term growth of culture and creativity industries in Zhejiang.

Among all the influencing factors, factors of markets have the smallest impact on the agglomeration of culture and creativity industries. As culture and creativity industries are different compared with other industries in that they belong to the ultimate demand-oriented industries, products and services are often aimed at the spiritual needs of the demanders. Catering to demanders' spiritual needs, the created needs are consumed to truly realize the production and sales purposes of culture and creativity industries. Nowadays, the consumption of culture, education and entertainment of both urban and rural people in the province has grown steadily, and the consumption pattern has been continuously innovated, which has injected new vitality into the development of culture and creativity industries. However, the proportion of consumption expenditure on culture, education and entertainment in the whole province is decreasing year by year, which runs counter to the rapid economic growth and is worrying. Maslow believed that different levels of demand will not be generated at the same time, and people's demand will be promoted to a higher level of spiritual culture only after meeting the lower level of demand, while the market demand for culture and creativity industries shows a higher level of demand. Therefore, the top priority is to raise the level of residents' consumption, which will help broaden the consumption market of culture and creativity industries and increase the output values of culture and creativity industries.

\section{Conclusions}

In this study, on the analysis of the relevant data (from 2012 to 2017) of the culture and creativity industries of each prefecture-level city in Zhejiang Province, the spatial distribution characteristics of culture and creativity industries agglomeration in Zhejiang Province including its 11 cities are analyzed by using the location entropy measure, and the influencing factors are analyzed by using the grey correlation, and the conclusions are as follows:

(1) The distribution and characteristic of culture and creativity industries in Zhejiang Province presents a trend of agglomeration. The agglomeration level of each city increases with the time, but the distribution is uneven with great differences. In Hangzhou, Zhoushan and Wenzhou, they have formed their own industrial advantages with high development level and strong agglomeration of space. Taizhou has a weak level of development and innovation of culture and creativity industries, so it should increase investment, stimulate demand and promote industrial development. 
(2) The research results of influencing factors of culture and creativity industry agglomeration in Zhejiang Province show that economic factors have the greatest influence on it, followed by technological, resource and market factors. Per capita postal and telecommunication expenses rank first among all variables, and the proportion of non-state-owned employees in culture and creativity industries to employed population in culture and creativity ranks last, reflecting that the agglomeration of development and innovation of cultural and creative industries in Zhejiang Province benefited from the drive of science and technology, and the lack of creative talents hindered the progress of the industry ${ }^{[6]}$. In view of this, in addition to providing economic and technical support for the development of culture and creativity industries, the government can intensify demand and guidance through culture and creativity, product innovation and other methods, increase residents' attention to the cultural industry, stimulate residents' cultural consumption demand, stimulate the economic growth of culture and creativity industries, vigorously develop education, cultivate innovative talents, and eliminate the imbalance between the supply of creative talents training and the market demand for creative talents, so that the culture and creativity industries can flourish.

\section{Acknowledgement}

The paper was support by Source of Research Funding: An Academic Achievement of Zhejiang philosophy and social science planning project in 2019 (Project No.: 19NDJC096YB).

\section{References}

[1] F. Zhen, "Influencing factors and countermeasures for the development of Wuxi cultural and creative industry cluster," Modern Economic Information, no. 31, pp.484-485, 2016.

[2] Z. J. Zhang, "Spatial distribution characteristics and influencing factors of cultural and creative industries in Jiangsu, Zhejiang and Shanghai," Zhejiang: Ningbo University, 2017.

[3] S. G. Jiang, L. N. Wang, “Agglomeration effect of cultural and creative industries in Beijing," Review of Economic Research, no. 45, pp. 62-71, 2017.

[4] D. Pan, "Level of clustering of cultural and creative industries and influencing factors." Hunan: Hunan University of Science and Technology, 2018.

[5] D. P. Zhang, "Factors influencing the development of cultural industry based on grey correlation analysis in Zhejiang Province," Journal of Zhejiang University of Industry and Commerce, no. 03, pp. 92-97, 2013

[6] L. Y. Wan, H. Z. Dong, P. Wu, et al., "Spatial agglomeration and development model of cultural and creative industries based on a case study of Ji'nan” Science and Technology Management Research, vol. 36, no. 7, pp. 185-189, 2016. 